\title{
Uma nova espécie de Cladomorphus Gray, 1835 (Phasmatidae, Cladomorphinae) de Minas Gerais, Brasil
}

\author{
Alice Fumi Kumagai ${ }^{1} \&$ Nilson Gonçalves da Fonseca²
}

'Departamento de Zoologia, Universidade Federal de Minas Gerais, Caixa Postal 486, 31.270-901 Belo Horizonte-MG. acfk@icb.ufmg.br ${ }^{2}$ Mestre em Ecologia, Conservação e Manejo da Vida Silvestre. ngfonseca@ bol.com.br

\begin{abstract}
A new species of Cladomorphus Gray, 1835 (Phasmatidae, Cladomorphinae) from Minas Gerais, Brazil. Cladomorphus trimariensis sp. nov., from Três Marias, Minas Gerais, is described and illustrated. The new species is different from C. phyllinus Gray, 1835 mainly for the operculum and micropylar plate of egg, absence of spines on the mid and hind legs, for the preopercular organ and distal projection of terga IV and V, that are less developed.
\end{abstract}

KEYWORDS. Phasmatodea; Phibalosoma; stick insect.

RESUMO. Uma nova espécie de Cladomorphus Gray, 1835 (Phasmatidae, Cladomorphinae) de Minas Gerais, Brasil. Cladomorphus trimariensis sp. nov. é descrita de Três Marias, Minas Gerais. A nova espécie difere de C. phyllinus Gray, 1835 principalmente pelo opérculo e placa micropilar do ovo, ausência de espinhos nas pernas médias e posteriores e pelas projeções distais nos tergos IV e V, que são menos desenvolvidas.

PALAVRAS-CHAVE. Bicho-pau; Phasmatodea; Phibalosoma.

A ordem Phasmatodea possui 13 famílias (Zompro 2004), 523 gêneros e 2.822 espécies, sendo 591 na América do Sul (Otte \& Brock 2005). A distribuição geográfica é ampla e com maior diversidade de espécies nos trópicos. Poucas coletas foram feitas na América do Sul e, ainda assim, possui o segundo maior número de espécies descritas, abaixo somente da Indomalásia, que teve coletas intensivas no leste da Ásia (Otte \& Brock 2005). Para o Brasil, mais de 200 espécies estão citadas (Zompro \& Domenico 2005).

Estes insetos alimentam-se de folhas e se assemelham a galhos, gravetos e folhas, são popularmente conhecidos como bicho-pau ou bicho-folha. Muitas espécies medem acima de $200 \mathrm{~mm}$ de comprimento (Brock 1992) e, apesar do tamanho grande, são insetos pouco estudados (Bradley \& Galil 1977; Zompro 2001), principalmente os sul-americanos (Otte \& Brock 2005), mas existem espécies com menos de $10 \mathrm{~mm}$ (Lima 1938).

Zompro \& Domenico (2005) publicaram um catálogo dos espécimes-tipos depositados em museus brasileiros, no qual constam 38 espécies de Phasmatodea descritas por Toledo Piza. As espécies: Phibalosoma paulense Toledo Piza, 1938; P. rochai Toledo Piza, 1938 e Bacteria tuberculata Toledo Piza, 1936 foram colocadas como sinônimos de Cladomorphus phyllinus Gray, 1835. Os gêneros Cladomorphus e Phibalosma foram descritos por Gray (1835), o primeiro com quatro espécies (C. phyllinus, $C$. ceratocephalus, $C$. dilatipes e $C$. perfoliatus) e o segundo com uma única espécie ( $P$. lepelletieri). No entanto, esta foi colocada como sinônimo de C. phyllinus e, desta maneira, o gênero Phibalosoma atualmente não é válido (Bradley \& Galil 1977). Assim, em Cladomorphus, sete espécies são válidas e as quatro citadas para o Brasil são: C. ceratocephalus Gray, 1835, C. michaelis
(Redtenbacher, 1908), C. phyllinus Gray, 1835 e C. rubus (Saussure, 1861) (Otte \& Brock 2005).

Muitas espécies de fasmatódeos foram descritas com base em um só exemplar e devido ao acentuado dimorfismo sexual, muitas foram colocadas em sinonímia (Zompro 2004). Clark $(1976,1979)$ apresentou chaves de identificação de gêneros de Phasmatodea com base nos ovos e afirmou que 5\% das espécies são conhecidas pelos ovos e eventualmente os gêneros poderão ser conhecidos pela morfologia do ovo. Assim, a espécie descrita aqui é baseada na morfologia do adulto, mas também na do ovo, mais especificamente, no opérculo e placa micropilar. A tomada de medidas dos ovos foi feita segundo Sellick (1997) e a nomenclatura da genitália segue a de Günther (1970).

\section{Cladomorphus trimariensis sp. nov.}

(Figs. 1 a 5)

Holótipo fêmea. Áptera, corpo robusto, textura rugosa, de cor castanho-clara acinzentada, mais escurecida na parte distal dos tubérculos. Corpo: comprimento 223,0 mm e largura 8,76 mm no metanoto (Fig. 1); cabeça: largura 0,74 do comprimento (7,7:10,3 mm); antenas filiformes com mais de 40 artículos, tão longas quanto as pernas anteriores e de coloração uniforme desde a base até o ápice. Vértice com seis tubérculos dispostos em duas fileiras, divergentes da parte anterior para a posterior, o tubérculo posterior o mais elevado. Tórax: protórax com largura 0,88 do comprimento (7,6: 8,6 mm); mesotórax com largura de 0,15 do comprimento $(7,2: 45,9 \mathrm{~mm})$ e metatórax com largura $0,26(8,7: 33,1 \mathrm{~mm})$ do comprimento. Pernas: fêmures I, II e III com 33,$3 ; 29,1$ e $35,8 \mathrm{~mm}$ de comprimento 

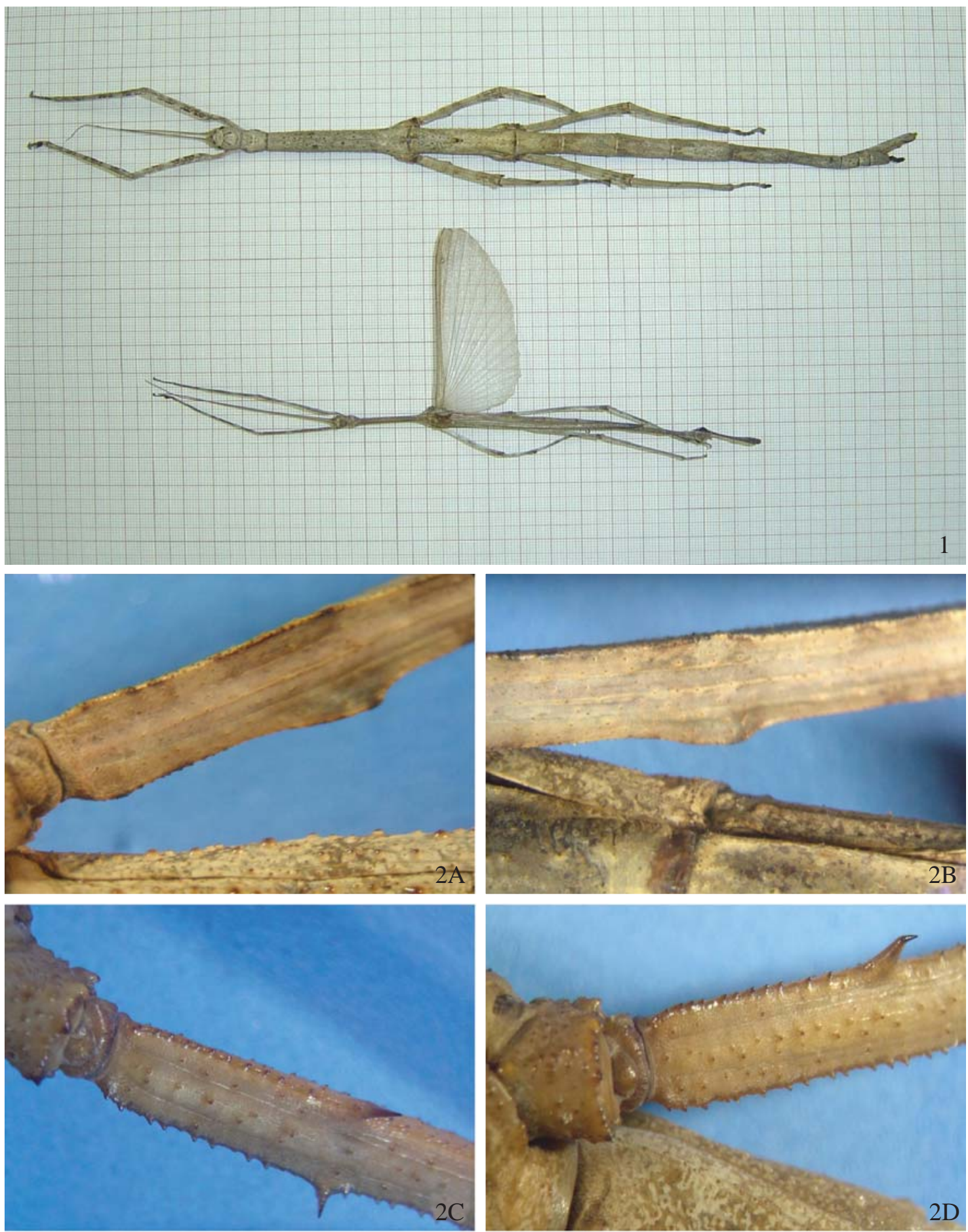

Fig. 1-2. 1. C. trimariensis sp. nov. - fêmea (holótipo) e macho (alótipo); 2. Fêmures médios (A) e posteriores (B) de C. trimariensis sp. nov. e fêmures médios (C) e posteriores (D) de C. phyllinus.

respectivamente; fêmures II e III sem espinhos na face ventral (Figs. 2A e 2B); tíbias I, II e III com os comprimentos: 35,7;31,3 e 39,7 mm respectivamente; tíbias II e III com pequena elevação, na parte mediana, na face dorsal e, ventralmente, com três carenas longitudinais (laterais e mediana), providas de minúsculos espinhos em toda a sua extensão; tarsos basais tão longos quanto os dois seguintes e com uma projeção no lado dorsal. Abdômen: tergo IV com projeção elevada e suavemente ondulada na margem distal; tergo $\mathrm{V}$ com projeção bastante reduzida (Figs. 3A e 3B); órgão pré-opercular no esterno VI com dois espinhos distintos na parte distal (Fig. 4A); opérculo com lados paralelos medindo $26,9 \mathrm{~mm}$ de comprimento. Cercos muito curtos, com 2,1 mm de comprimento. 



Fig. 3-5. 3. Tergo IV (A) e tergo V (B) de C. trimariensis sp. nov. e tergo IV (C) e tergo V (D) de $C$. phyllinus; 4. Órgão pré-opercular de $C$. trimariensis sp. nov. com dois espinhos distais (A) e órgão pré-opercular de C. phyllinus com três espinhos distais (B); 5. Ovo. Opérculo de $C$. trimariensis sp. nov. (A); opérculo de C. phyllinus (B); vista lateral e frontal de C. trimariensis sp. nov. (C e D), respectivamente.

Ovo: cápsula com superfície de textura lisa, marrom-clara com manchas amarelo-palha e manchas irregulares marromescuras e pretas. Comprimento total $4,8 \mathrm{~mm}$, largura $2,8 \mathrm{~mm}$ e altura 3,8 mm. Peso 0,033 gramas. Opérculo de cor preta com retículos fechados hexagonais e pentagonais, comprimento $0,42 \mathrm{~mm}$, largura $1,7 \mathrm{~mm}$ e altura 2,7 mm (Fig. 5A). Placa micropilar medindo 0,6 a 0,7 do comprimento do ovo, com margem anterior próxima à margem do opérculo (Figs. $5 \mathrm{C} \mathrm{e}$ $5 \mathrm{D})$.

Macho: corpo delgado, de coloração levemente mais escura que a da fêmea; comprimento do corpo 134,0 mm e largura 2,2 
mm no mesonoto (Fig. 1). Cabeça: textura e coloração como na fêmea; largura 0,84 (3,7:4,4 mm) do comprimento; antenas filiformes com mais de 40 artículos, tão longas quanto as pernas anteriores e de coloração uniforme desde a base até o ápice. Tórax: textura e coloração semelhantes às da cabeça; protórax com largura 0,7 do comprimento $(3,1: 4,4 \mathrm{~mm})$; mesotórax com largura 0,1 (2,2:21,1 mm) do comprimento; metatórax com 26,4 mm de comprimento. Pernas: fêmures I, II e III, com 29,5; 24, 1 e $31,0 \mathrm{~mm}$ de comprimento. Tíbias I, II e III com comprimentos: 33,$2 ; 24,2$ e $30,5 \mathrm{~mm}$. Tíbias II e III com carenas longitudinais (laterais e mediana) com espinhos inconspícuos. Asas anteriores: de consistência pergaminosa, com 9,2 mm de comprimento e as posteriores membranosas, com $65,4 \mathrm{~mm}$ que, em repouso, cobrem até o tergo IV abdominal. Abdômen: tergo $\mathrm{X}$ alargado suavemente para o ápice.

Material-tipo. Holótipo fêmea, BRASIL, Minas Gerais. "Três Marias, 2001 N. G. Fonseca col.". Alótipo e parátipos estudados neste trabalho foram criados em laboratório (seis fêmeas e 16 machos) a partir dos ovos da fêmea (holótipo) coletada em uma área de cerrado. O material está depositado na Coleção de Entomologia do Departamento de Zoologia, Instituto de Ciências Biológicas da Universidade Federal de Minas Gerais, em Belo Horizonte, Minas Gerais.

Etimologia - nome alusivo ao local de coleta do espécime, município de Três Marias.

\section{DISCUSSÃO}

Cladomorphus trimariensis sp. nov. é semelhante a $C$. phyllinus pelo aspecto geral, coloração do corpo, fêmea áptera, macho alado, tamanho e forma do ovo, e também pela sua planta alimentícia (em cativeiro alimentam-se de Psidium guajava L. e Eugenia uniflora L.). Difere, entretanto, nos seguintes caracteres: ausência de espinhos no terço basal dos fêmures II e III, na parte ventral; órgão pré-opercular distalmente com dois espinhos distintos e sem o espinho mediano; opérculo da fêmea com os lados longos e paralelos; o tergo IV com projeções distais reduzidas e a margem reta, o tergo $\mathrm{V}$ com projeção distal bastante reduzida semelhante a um pequeno espinho; o opérculo do ovo com retículos fechados e a placa micropilar longa, de 0,6 a 0,7 do comprimento do ovo. Em C. phyllinus podem ou não, ocorrer fileiras de tubérculos no vértice; o terço basal da face ventral do fêmur II com dois espinhos de tamanhos desiguais (Fig. 2C) e o fêmur III com um único espinho conspícuo (Fig. 2D); o tergo IV com projeção distal desenvolvida, levemente arqueada e marginada de pequenos espinhos irregulares (Fig. $3 \mathrm{C}$ ), o tergo $\mathrm{V}$ com projeção distal mais desenvolvida que em C. trimariensis, e esta de forma diferente de um espinho (Fig. 3D); órgão préopercular distalmente com três espinhos distintos, o mediano mais elevado e desenvolvido (Fig. 4B); o opérculo da fêmea afilado para o ápice; o opérculo do ovo com alguns retículos fechados na parte central e raios alongados no bordo e os retículos abertos (Fig. 5B); a placa micropilar de posição mediana e mais curta, com 0,4 a 0,5 do comprimento.

Agradecimentos. Os autores agradecem à Dra. Danúncia Urban, da Universidade Federal do Paraná, pela leitura do manuscrito; ao Dr. Sinval Silveira Neto, da Escola Superior de Agricultura "Luiz de Queiroz" (USP), por tornar possível a comparação com exemplares de C. phyllinus; às biólogas Flávia Santos Faria e Tatiana Mingote Ferreira de Ázara, pela ajuda na criação dos exemplares em laboratório e à técnica de laboratório do Departamento de Zoologia, ICB/UFMG, Dalva Maria da Rocha Luz, pelos exemplares e ovos de C. phyllinus para comparação.

\section{REFERÊNCIAS}

Bradley, J. C. \& B. S. Galil. 1977. The taxonomic arrangement of the Phasmatodea with keys to the subfamilies and tribes. Proceedings of the Entomological Society of Washington 79: 176-208.

Brock, P. D. 1992. Rearing and studying stick and leaf-insects. The Amateur Entomologist, volume 22. 73 p.

Clark, J. T. 1976. The eggs of stick insects (Phasmida): a review with descriptions of the eggs of eleven species. Systematic Entomology 1: $95-105$.

Clark, J. T. 1979. A key to the eggs of stick and leaf insects (Phasmida). Systematic Entomology 4: 325-331.

Gray, G. R. 1835. Synopsis of the species of insects belonging to the family of Phasmidae. Longman, Rees, Orme, Brown, Green and Longman, London. 48 p.

Günther, K. 1970. Cheleutoptera (Phasmoidea). In: Taxonomist's glossary of genitalia in insects. TUXEN, S. L. (ed.) $2^{\text {th }}$ edition. J. Jorgensen \& CO. p. 58-61.

Lima, A. da Costa. 1938. Insetos do Brasil. $1^{\circ}$ tomo. Escola Nacional de Agronomia, Rio de Janeiro. Série didática. $470 \mathrm{p}$.

Otte, D. \& P. Brock. 2005. Phasmida species file: catalog of stick and leaf insects of the world. $2^{\text {th }}$ edition. Insect Diversity Association at the Academy of Natural Sciences, Philadelphia. $414 \mathrm{p}$.

Sellick, J. T. C. 1997. Descriptive terminology of the phasmid egg capsule, with an extended key to the phasmid genera based on egg structure. Systematic Entomology 22: 97-122.

Zompro, O. 2001. A generic revision of the insect order Phasmatodea: the New World genera of the stick insect subfamily Diapheromeridae: Diapheromerinae $=$ Heteronemiidae Heteronemiinae sensu Bradley \& Galil, 1977. Revue Suisse de Zoologie 108: 189-255.

Zompro, O. 2004. Revision of the genera of the Areolatae, including the status of Timema and Agathemera (Insecta: Phasmatodea). Abhandiungen des Naturwissenschaftlichen Vereins in Hamburg 37: 1-327.

Zompro, O. \& F. C. Domenico. 2005. Catalogue of the type material of Phasmatodea (Insecta) deposited in Brazilian Museums. Iheringia, Ser. Zool. 95: 255-259. 